\title{
Environmental problems of the agro-industrial complex: a lawyer's view
}

\author{
Svetlana Miroshnik ${ }^{1, *}$, Olesya Nemykina $^{2}$, Ekaterina Bochkareva $^{3}$, Svetlana Kozhushko ${ }^{3}$, \\ and Olga Solovyeva ${ }^{3}$ \\ ${ }^{1}$ Russian State University of Justice, 69, Novocheremushkinskay str, 117418, Moscow, Russia \\ ${ }^{2}$ Don State Technical University, 162, Socialist str, 344000, Rostov-on-Don, Russia \\ ${ }^{3}$ Russian State University of Justice, North Caucasian Branch, 187/1, Levanevskiy str, 350002, \\ Krasnodar, Russia
}

\begin{abstract}
The relevance of the research topic is caused by the fact that the agro-industrial complex has a significant impact on the state of the environment. The agro-industrial complex is the most important element of the economic life of the absolute majority of countries. Its functioning is objectively necessary - enterprises that are part of the agro-industrial complex provide society with food and a number of important goods made from agricultural raw materials. The work of the agro-industrial complex also has the other side of the coin. Mechanization and automation of production lead to a quantitative and qualitative deterioration in the state of land, water and air resources. The purpose of the study is to highlight the environmental problems of the agro-industrial complex, to formulate proposals for their solution. The methodological basis of the study was scientifically grounded integrative legal thinking. The conclusion is made that the regulation of relations arising in the process of functioning of the agro-industrial complex is ensured through the application of social and technical norms. Environmental quality standards are of particular importance for solving environmental problems of the agro-industrial complex. They should be scientifically based and binding on all subjects of law.
\end{abstract}

\section{Introduction}

The term "economics" is one of the most popular, familiar words, which is actively used in professional and everyday life. It is believed that for the first time, the word "economics" was used by the famous Greek thinker Xenophon in his scientific works in the 4th century BC.

Today, it is used to mean:

- economic activities of the company,

- totality of social relations developing in the process of production, distribution, exchange and consumption,

\footnotetext{
* Corresponding author: miroshnik67@mail.ru
} 
- systems of the humanities that study the essence of the processes of production, distribution, exchange and consumption.

Despite the "venerable" age of the term "economics", scientists cannot find agreement on the solution of the issue concerning the moment of emergence of economic relations until now. Some believe that economic relations began to develop after the victorious bourgeois revolutions as a result of the gradual transformation of early capitalist ties. Only those social relations that are based on the principles of free enterprise and competition can be called economic, when such attributes of the market economic system as profit, loss, and price appear. If there are no economic incentives for development, then there can be no talk of any economy under the conditions of a slave-owning or feudal system.

This position is highly controversial. The theory of Karl Marx about socio-economic formations that successively replace each other and show the progressive development of human society in all spheres of its life seems to be very convincing.

At the stage of the primitive communal system, people took everything they needed from nature by gathering and hunting. They took just as much as was needed for physical survival. A person who had just emerged from nature, experiencing both a feeling of fear and a sense of reverence for it, was anxious about the surrounding reality. Unlike animals, he was able to control his behavior. But this did not happen right away - Homo sapiens appeared only about 40 thousand years ago. He developed as a biological species. And this is the merit of nature. It is to nature, which created the conditions for the development of all living things, that man owes his life. The emerging social regulators allowed a person to become a biosocial being, which is guided not only by biological, but also by social laws. Activity, maybe specific, maybe primitive from the standpoint of today's man, but social one, demanded the development of social means of its regulation. The answer to this request was the emergence of certain stereotypes of behavior, principles and rules passed down from generation to generation.

It should be noted that the norms of primitive society regulated not only the relations between its members, but also determined the nature of the relationship with the surrounding reality. They had a pronounced syncretic character. In the primitive taboos, totemic systems that have developed among a number of peoples, there is a respectful attitude towards nature, an understanding of it as the beginning of life.

The Neolithic Revolution became a turning point in the life of human society. The transition from an appropriating to a producing economy led to the complication of social relations, the emergence of property relations, the emergence of social inequality and, finally, the state. The state-organized society has acquired new unique opportunities for its development. But in pursuit of satisfying his ever-increasing needs, man gradually began to forget about his natural roots.

Initially, at the stage of gathering, hunting, mastering and improving agricultural skills, a person interacted with nature, in general, without violating its integrity, without interfering with the circulation in nature. Already at this stage, he thought not only about today, but also tomorrow. Monuments of law contained norms aimed at forming a respectful attitude to the surrounding reality. They stimulated, albeit by negative means of influence (fines, other punishments), respect for the land and water. So, for example, the laws of Hammurabi touched upon many aspects of agriculture, including the issues of rational water use. A peasant who did not follow the trenches in the fields and who allowed the water to leave was obliged to reimburse the cost of the unproduced crop. Public consciousness was built on the understanding of the dependence of the life of society on the rhythms of nature. On one of the pyramids of Ancient Egypt, an inscription has been preserved, which, according to experts, was made in the XXI century BC. It says: "People will die from inability to use the forces of nature and from ignorance of the true world". 
Today we only marvel at the wisdom and sagacity of the ancient thinkers. We have not only lost a lot of ancient knowledge, but our consciousness has been deformed under the slogan "man is the crown of nature", the desire of a number of subjects to obtain fabulous profits at any cost.

Domestic and legal science studies various aspects of the negative impact of human economic activity on existing ecosystems. Scientists rightly draw attention to the fact that restoring the disturbed balance in nature requires a lot of time and effort [1, P. 335-339]. Intervention in the circuit leads to unpredictable consequences. Humanity still feels, in our opinion, only the first, initial results of its frivolity, although representatives of science have long sounded the alarm. The conducted research, in particular, made it possible to establish:

- drastic changes in the nature of the steppes of the Middle Urals in the form of a decrease in the population of steppe flora and fauna, the appearance of "uninvited" guests traditionally living in forest zones [2, P. 21-31];

- negative effect of oxytetracycline on soil microorganisms [3];

- the spread of invasive plant species as a result of climatic changes and the expansion of their range of life (for example, South Korea, but it seems that the conclusions drawn are also relevant for other regions of the planet, because the dispersal of invasive plant species is a real threat to food security) [4];

- $\quad$ causes of land degradation (natural and anthropogenic ones) [5].

Scientists not only identify environmental problems, but also propose specific ways to solve them. In this connection, for example, the proposals of a number of researchers concerning the reclamation of former landfills, the criteria for choosing plants necessary for the restoration of soil characterized by high density and low content of organic and nutrient substances [6] deserve close attention, as well as planning of state land use [7], the need to develop and adopt action plans for long-term restoration of ecosystems [8, P. 415]. The findings of A.G. Vasiliev, reflecting new approaches to understanding revolutionary ecology, are of particular interest [9, P. 102-114].

The most important element of the economic sector of life of the absolute majority of modern states is the agricultural industry. The agricultural industry, like other sectors of the economy, makes a significant contribution to climate change. Drainage, or vice versa, irrigation of the land carried out without an accurate assessment worsens the condition of the soil, violates the condition of natural ecosystems.

The restoration and preservation of an environment favorable for all life on the planet has become a major global challenge, acutely highlighted in the second half of the last century. The rapid development of industry and agriculture caused by the influence of scientific and technological progress, which grew into scientific and technological one, led to a sharp deterioration in the state of nature. Uncontrolled deforestation, air and nature pollution have led to a significant decrease in natural resources, disruption of natural ecological ties, many of which cannot be restored today (which means their irreversible loss for humanity with all the ensuing consequences).

The agro-industrial complex, as the largest systemic entity in the economic life of society, has a very tangible effect on the environment. Therefore, without neutralizing such a negative impact, restoring the disturbed natural balance, it is impossible to improve the quality of human life and labor.

The analysis of special sources indicates that the environmental aspects of the agroindustrial complex regulation mechanism require further improvement. In legal science, there is no unity in understanding the legal consolidation of the right to a safe favorable environment at the international level, the significance of this measure of possible behavior for the development of the agro-industrial complex. In a number of cases, the issues of improving social and technical norms, without which the successful development of the agro-industrial complex is impossible, are outside the area of attention. Constant scientific 
monitoring of judicial practice presupposes a systematic analysis of court decisions, especially decisions of the European Court of Human Rights, in order to develop common approaches to solving environmental problems, to comprehend the peculiarities of judicial resolution of environmental cases, to search for, as Jeff Todd said, "sense of justice" in taken decisions [10, P. 169-233]. Modern realities also speak of the relevance of the study of climate security (365-366) and its impact on the functioning of the agro-industrial complex [11, P. 321-366].

\section{Materials and methods}

The research was carried out on the basis of the provisions of scientifically grounded integrative legal thinking. The systematic, logical, formal legal methods of cognition were used. The author's conclusions were the result of analysis and synthesis of the principles and norms of national and international law, the provisions of domestic and foreign sciences. The empirical basis of the article is the decisions of the European Court of Human Rights, the normative basis is the provisions of a number of international treaties (the Vienna Convention for the Protection of the Ozone Layer, the Convention on Biological Diversity, the Convention on Persistent Organic Pollutants), which are of fundamental importance for the legal support of the agro-industrial complex.

When carrying out the study, the authors proceeded from the understanding of the agroindustrial complex as a set of a number of interconnected sectors of the economy, characterized by the unity of goals and management technologies, specifically, those sectors of the economy within which the production and processing of agricultural raw materials and the manufacture of appropriate products from it are carried out. Accordingly, the nature of the final product unites the subjects of the food and non-food sectors within the agro-industrial complex.

The authors took into account that the main link in the agro-industrial complex is agriculture. It is its alpha and omega, which cannot function without sectors of the economy providing the necessary infrastructure, on the one hand, and without which the solution of food programs and the work of industries processing agricultural products is impossible, on the other.

The agro-industrial complex systemically connects:

- industries that provide agriculture and related industries with means of production (creating infrastructure, for example: mechanical engineering, production of mineral fertilizers),

- agriculture (main, initial link),

- industries that provide procurement, storage and processing of agricultural raw materials, as well as the sale of final products, for example: dairy, meat, feed industry (Fig. 1). 


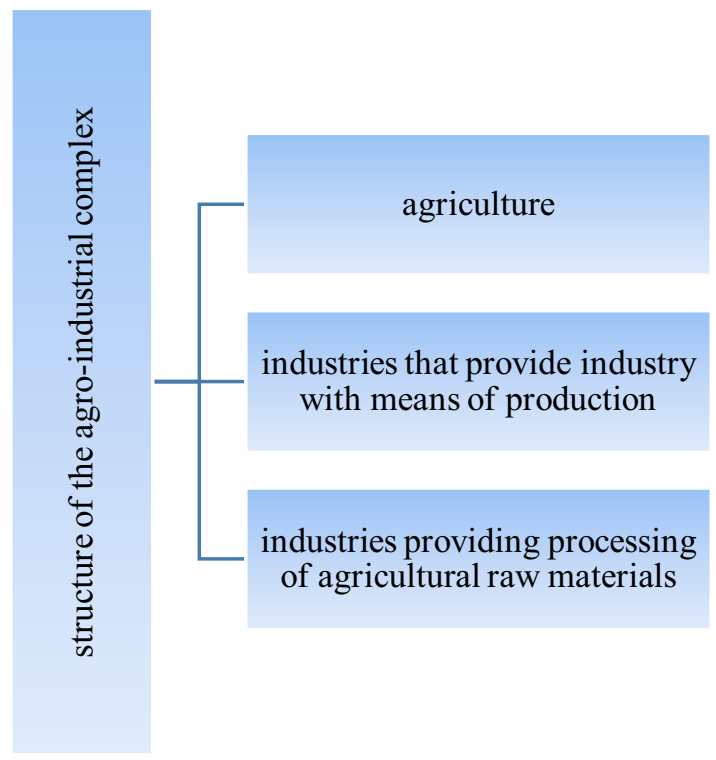

Fig. 1. Structure of the agro-industrial complex.

The agro-industrial complex has a significant impact on the environment. Compaction of the soil, destruction of the fertile layer, chemicalization of water, air and land resources, and predatory use of fish resources are just some of the aspects of the environmental problems.

A person cannot do without the agro-industrial complex. Its task is to ensure such conditions for the functioning of all sectors of the economy in order to provide itself with food and necessary goods produced from agricultural raw materials. This can be done only through a clear regulation of social relations. Moreover, in this case, it is important not to forget about the systematic approach, which allows not only seeing the nature of the problems, but also developing proposals for their solution, taking into account the complex connections between them.

\section{Results}

The development of civilization has determined the formation and functioning of many systems of principles and norms that regulate both relations in society and its relationship with the surrounding reality. The subject composition allows us to single out, first of all, groups of technical and social norms. All of them are equally important for ensuring the stable, safe and efficient functioning of the country's agro-industrial complex.

Technical standards represent the principles and rules for the handling of tools, technical devices, and forces of nature. Their appearance is caused by the need to meet the needs of society for security, ensuring safe conditions for its life. Scientific and technological progress, which grew into a scientific and technological revolution, on the one hand, made it possible not only to rise to a qualitatively new level, to develop, for example, the digital economy, but also to give rise to numerous problems of an ecological, legal, ethical nature, on the other. The issues of nature protection and ensuring the ecological well-being of the planet are becoming more and more acute. Man is in a dual position. On the one hand, he is a subject of law, the only living being who, in the course of 
evolution, managed to develop the ability to self-regulate. On the other hand, it still remains an object of nature, whose life depends on both the social and natural environment.

The law, influencing the consciousness and behavior of people, is the most important element of governance, which is important both for the socio-economic and technical life of society. A person strives to develop and introduce new technologies, improve the quality of goods (works, services), improve working conditions and his life, and raise it to a fundamentally different level.

Understanding the importance of a number of technical norms, the subject of lawmaking makes them generally binding by recording them in the relevant regulatory legal acts that have different legal powers. The diversity of technical standards that are essential for the agro-industrial complex is shown in Figure 2.

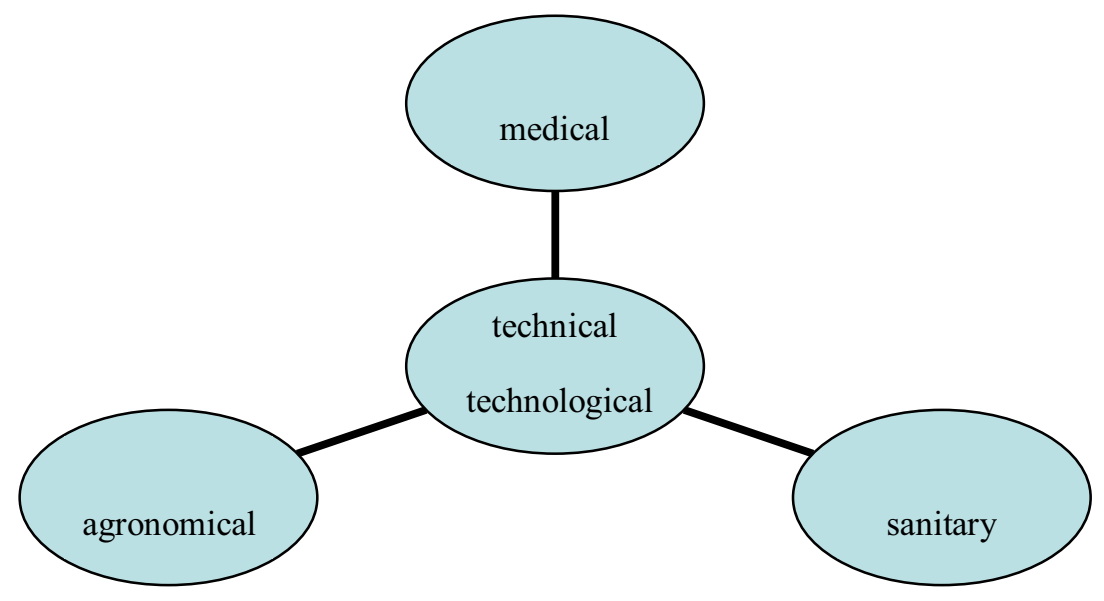

Fig. 2. Diversity of technical standards.

The Universal Declaration of Human Rights has enshrined the right of everyone to a standard of living that is necessary to maintain the health and well-being of a person and his family members [12]. The country's agro-industrial complex plays an important role in ensuring its implementation. It should:

- $\quad$ provide society with the necessary environmentally friendly food (without this, it is impossible to maintain human health), products made from agricultural raw materials,

- together with other sectors of the economy, create and maintain safe living and working conditions,

- $\quad$ act as an integral element of an integrated, comprehensive system of nature protection, restoring the disturbed balance in nature and preventing the emergence of new environmental problems and troubles.

Society is increasingly in need of such norms of environmental law, which, taking into account the previous social experience, would reflect a new model of civilization development, based on the priority of the interests of nature. Environmental problems have long outgrown the borders of one state. Their solution is possible only by the forces of the world community. Without nature, safe living and working conditions, human life is impossible.

In the conditions of the scientific and technological revolution, the issues of establishing environmental quality standards are of particular interest from a scientific and practical 
point of view. These standards are the rules of conduct that establish the maximum permissible standards of impact on the natural environment, the implementation of which guarantees the environmental safety of both humans and the environment, the possibility of preserving and developing their genetic fund. These include, for example, the standards for the maximum permissible concentrations of harmful substances, the standards for the maximum permissible levels of noise, radiation exposure.

Environmental quality standards are also important for the agro-industrial complex. The state establishes:

- maximum permissible norms for the use of agrochemicals in agriculture, chemicals in the production of food, standards for protective and sanitary zones;

- requirements for the construction and reconstruction of structures, other facilities.

It is important that the states, when establishing the standards under consideration, rely on scientifically grounded recommendations, do not follow the lead of the largest corporations, which set themselves to only receive profits and do not care about the future. Yes, technical norms are not social, but this does not negate their social significance as an essential element in ensuring a safe life on the planet. A person studies the properties of substances, the features of certain phenomena, objective laws and trends in the interaction of natural forces, recognizes their usefulness and the possibility of using them to improve the conditions of their life and work.

Social relations arise between various subjects of law regarding:

- implementation of technical standards,

- carrying out legal expertise (in this case, legal expertise is considered in the broad sense, as complex, including all types of expertise defined by the rules of law, including environmental one) of draft regulatory legal acts, programs, standards,

- control over the implementation of the decisions made.

Technical norms cannot operate outside of society, they are real only in conjunction with social norms.

The implementation of technical norms has repeatedly become the subject of litigation. The natural environment is protected by the principles and norms of both national and international law. The latter, unfortunately, has some regrettable gaps.

The fact is that the Convention for the Protection of Human Rights and Fundamental Freedoms does not legally recognize the human right to a favorable, safe environment [13]. The presence of this gap is caused by the action of mainly objective reasons. During the years of its adoption, environmental problems had not yet sounded so loud, states were painfully recovering from the Second World War. Unfortunately, the pursuit of profit, momentary receipt of benefits was accompanied by a one-sided predatory attitude towards nature. The situation was aggravated by a lack of understanding of the scale of the harm. As a result, the issue of recognizing the right to a favorable, safe environment as an essential human right, naturally arising from the human right to life and personal dignity, has become acute today.

To date, the necessary amendments to the Convention have not yet been made, but the enforcement activity takes into account the realities of the time. Thanks to the activities of the ECHR, many provisions of the international document under consideration began to be considered taking into account the environmental interests of man, society and nature.

For example, in the case of Di Sarno and Others v. Italy (application no. 30765/08), the European Court has reaffirmed the duty of states to provide access to information about threats arising not only from risky and dangerous human activities, but also having a natural character. The transfer of a number of publicly significant functions to private companies does not release public authorities from responsibility for their implementation [14].

The court considered the materials of the case based on the provisions of the European Convention in their systematic relationship with the UN Convention on Access to 
Information, Public Participation in Decision-Making and Access to Justice in Environmental Matters (adopted in Aarhus, June 25, 1998). Unfortunately, to date, the Russian Federation has not become a party to this Convention, which seems to be a serious omission. The UN Convention legally recognized the right of "every person of present and future generations to live in an environment adequate to his or her health and well-being" [15]. The signatories committed themselves to guaranteeing the right to access to information, to public participation in decision-making, to access to justice in environmental matters, and to assist in the realization of this right.

An analysis of the "environmental cases" of the ECHR shows that the court makes decisions based primarily on a systemic interpretation of Article 8, which enshrines the human right to respect for private and family life, correspondence and home. This interpretation lays the foundation for recognizing the existence of the human right to a healthy environment [16, P. 3]. Without denying this progressive movement of judicial practice at the international level, it should be noted that the real right to a favorable environment has long been in the air. Courts, including Russian ones, have stood guard over the environmental interests of man and the planet, but this is still not enough. It is necessary that the considered measure of possible behavior received legal recognition both at the national and international levels by making additions, in particular, to Article 2 of the European Convention on Human Rights. This is fundamentally important, in our opinion, since the ecological situation is only getting worse every day, the number of negative risks dangerous to human life and health is increasing. The imbalance in nature as a result of illconsidered, predatory economic activities of man has led not only to environmental pollution, but also to an increase in natural disasters. Climate change threatens society with new troubles.

Environmental issues affect human rights in different ways. They can be expressed in:

- the absence of environmental quality standards or their ignoring in practice,

- failure to bring to the attention of people accurate information about the risks of negative impact, the scale of man-made accidents,

- $\quad$ difficulties in exercising the right to compensation for harm and damage caused by man-made accidents,

- $\quad$ lack of proper control over the elimination of the consequences of man-made accidents,

- $\quad$ ignoring public opinion when making decisions that are important for the environmental situation.

It should be borne in mind that the human right to a safe, favorable environment is impossible without legal restrictions expressed in prohibitions of an absolute and relative nature, without clear measures of legal liability for violation of the principles and norms of international and national environmental law. When planning its activities, the legal entity must take into account that the right to use the property is not absolute. As rightly noted in the literature, the protection of the natural environment can be a legitimate reason for its limitation [17, P. 8].

Attention should be paid to one more important point - the recognition of the right to a safe, favorable environment presupposes a serious change in the existing level of legal awareness. And this concerns, first of all, the authorized subjects who guard human rights. Therefore, we believe that the ECHR's understanding of environmental threats as an integral part of the life of every modern city does not correspond to the goals of environmental activities [18]. An atmosphere of intolerance and inadmissibility of violation of the principles and norms of environmental law must be created in every country throughout the world. 


\section{Discussion}

Judicial practice and the realities of our time have revealed a problem arising in the process of implementing the agro-industrial complex in terms of environmental issues. The fact is that the ECHR proceeds from the fact that negative changes in the environment in themselves cannot entail an automatic recognition of violations of the provisions of the European Convention on Human Rights. In this regard, the case of Kyrtatos v. Greece (application no. 41666/98) deserves attention [19]. The applicants complained about the deprivation of their picturesque nature as a result of the draining of the bog near their house and the inconvenience caused by the noise and night lights of a construction site that had appeared on the site of the former bog. Based on this, the court divided the complaint into two parts. On the first requirement, a highly controversial position was formulated. The ECHR acknowledged that the damage to the flora and fauna has not been proven. The fact that the bog ceased to exist as a specific system does not violate the rights of the applicants. The argument that the bog was no longer a habitat for wild animals and plants was not taken into account.

The ECHR considers that there is a violation of the provisions of the Convention only when there is a serious danger to human health. In the case of Lopez Ostra v. Spain (application no. 16798/90) [20], the court found that the applicant's rights had been violated as a result of the construction and operation of a waste treatment plant. Industrial activity was accompanied by emissions of harmful substances, which, according to medical documents, caused harm to the health of people close to the applicant. At least two questions arise: why an individual subject cannot bring a claim in defense of the interests of nature when he sees or assumes that the implementation of a project, no matter what benefits of civilization it brings, will lead to a change in the existing ecosystem? Threats to human life and health can be potential and real. The phrase "serious health hazard" used by the court is vague. Today, no expert can predict the consequences of environmental degradation for the near and distant future. Therefore, we believe that human rights are violated whenever there is environmental degradation. At first glance, minor changes can turn into disastrous consequences in the distant or not very distant future, given the interconnection of all processes in nature.

The analysis of environmental cases by the ECHR highlighted another major problem. In many environmental decisions, the court pays attention to the quality of life, considering this category to be subjective and therefore hardly amenable to precise definition [21]. We agree that, in economic and social terms, it is still impossible to achieve a unified understanding of the quality of life in the world. But the issues of human survival, which awaits us in the near future as a natural result of the accumulation of environmental problems, require the development of uniform standards for the quality of the environment. They must be developed within the framework of the UN and quickly implemented into national legal systems. An effective system of international and national monitoring of their compliance must be established.

Considering the environmental problems of the functioning of the agro-industrial complex, one more important aspect should be mentioned - the importance of the scientific approach. Science as a system of knowledge has given mankind a lot. But in some cases, its one-sided approach turns out to be fatal for nature and man. For example, it is no secret that agricultural chemistry, which has developed rapidly in recent centuries, almost did not pay any attention to the environmental consequences of the use of fertilizers and other chemical elements in agriculture, violation of the rules of farming, pollution of rivers and other water resources. The further nature of the influence of the agro-industrial complex on the environment, human life and working conditions largely depend on the restructuring of science itself, and increasing attention to solving its problems on the part of the state. Only 
by joint efforts it is possible to create such a system of state administration of the agroindustrial complex, which will not only solve existing environmental problems, but also prevent the emergence of new ones. It is important not to forget the provisions of the Stockholm Declaration - changes in the world around us can bring both good and irreparable damage, creating a real threat to the life on the planet [22].

It should also be borne in mind that the environmental problems of the agro-industrial complex, like many others, have a pronounced political character. In this regard, it would be great if Nathaniel Levy's call to put climate in the first place when solving political issues would materialize [23, P. 479-506]. Its changes affect not only the natural, but also the social environment [24, P. 120-174]. This is not only a "super-evil" environmental problem, it is an accelerator and catalyst of devastating consequences for our security.

Conclusions: The functioning of the agro-industrial complex is objectively necessary in order to meet the needs of society for food and goods made from agricultural raw materials. The agro-industrial complex has a significant impact on nature, life and human working conditions. The resulting environmental problems require immediate solutions based on a systematic approach.

The Constitution of the Russian Federation has enshrined the human right to a healthy environment. But this is clearly not enough today, since environmental problems have long outgrown the framework of one state. They can only be solved by joint efforts of the international community. The right to a safe and healthy environment must be recognized internationally as a natural human right. Without it, all other natural rights, first of all, the human right to life, turn out to be fiction in modern conditions. This measure of possible behavior structurally includes the right to receive reliable information about the environmental situation, the right to participate in the discussion of projects, the implementation of which may have an impact on the natural environment, as well as the right to access to justice as a means of protection.

Technical standards play a significant role in solving environmental problems caused by the agro-industrial complex. The state of nature today is such that it is necessary to adopt uniform standards for the quality of the environment at the international level, to create an effective mechanism for international and national control of their observance.

Effective improvement of legal and technical principles and norms is possible only if the decisions made are scientifically based (Figure 3).

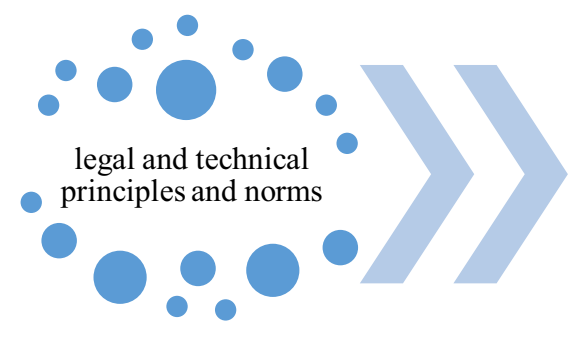

science, agro-industrial complex, human

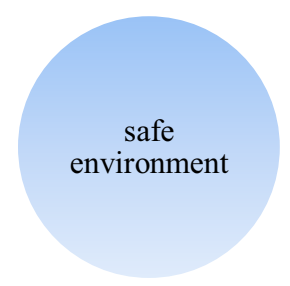

a condition for the life of nature and society

Fig. 3. Mechanism for restoring ecosystems.

Research should be aimed at creating a coherent mechanism for restoring disturbed ecosystems, skillfully using the laws of natural circulation in the life of society, creating safe living conditions for nature and society as a single indissoluble whole. 


\section{References}

1. I.N. Mikhailova, Russian Journal of Ecology, 48 (4), 335-339 (2017) DOI: 10.1134/S1067413617030110

2. N.V. Zolotareva, M. P. Zolotarev, Russian Journal of Ecology, 48 (1), 21-31 (2017) DOI: 10/1134/S106741361606014X

3. N. Danilova, P. Galitskaya, S. Selivanovskaya, Journal of Ecology and Environment, 44 (10) (2020) https://doi.org/10.1186/s41610-020-00154-x

4. P. Adhikari, JY. Jeon, H.W. Kim et al., Journal of Ecology and Environment, 43 (36) (2019) https://doi.org/10.1186/s41610-019-0134-3

5. K. Gashu, Y. Muchie, Journal of Ecology and Environment, 42 (17) (2018). https://doi.org/10.1186/s41610-018-0077-0

6. Song, Journal of Ecology and Environment, 42 (30) (2018) https://doi.org/10.1186/s41610-018-0089-9

7. M. Squillace, Harvard Environmental Law Review, 43 (2) 415-478 (2019) https://harvardelr.com/wp-content/uploads/sites/12/2019/08/43.2-Squillace.pdf

8. S.B. Zellmer, S.J. Panarella, O.F.Wood, Harvard Environmental Law Review, 44(2), 367-415 (2020) https://harvardelr.com/wp-content/uploads/sites/12/2020/08/44.2Zellmer.pdf

9. A.G. Vasilyev, Russian Journal of Ecology, 50 (2), 102-114 (2019) DOI: $10.1134 /$ S1067413619020103

10. J. Todd, A "Sense of Equity" in Environmental Justice Litigation. Harvard Environmental Law Review., 44 (1), 169-233 (2020)

11. M.P. Nevitt, Harvard Environmental Law Review, 44 (2), 321-366 (2020) https://harvardelr.com/wp-content/uploads/sites/12/2020/08/44.2-Nevitt.pdf

12. The Universal Deklaration of Human Rights (Full Version) https://www.coe.int/en/web/compass/the-universal-declaration-of-human-rights-fullversion-

13. Convention for the Protection of Human Rights and Fundamental Freedoms. Rome, 4.XI.1950 https://www.echr.coe.int/Documents/Convention_ENG.pdf

14. C.O. Di Sarno, et al., v. Italy (Application No. 30765/08) Judgment [Extracts] Strasbourg 10 January 2012 Final 10/04/2012

15. The United Nations Convention on Access to Information, Public Participation in Decisionmaking and Access to Justice in Matters

16. I. A. Cenevska. Journal of environmental Law, 28 (2), 301-324 (2016)

17. Manual on human rights and the environment. Council of Europe. 2012. P.https://www.echr.coe.int/LibraryDocs/DH_DEV_Manual_Environment_Eng.pdf

18. Resolution of the ECHR 10.02.2011 «Dubetska and Others v. Ukraine» (complaint $N$ 30499/03) http://www.echr.coe.int

19. Case Of Kyrtatos v. Greece (Application No. 41666/98) Judgment Strasbourg 22 May 2003 Final 22/08/2003

20. Case of López Ostra V. Spain. (Application no. 16798/90) Judgment Strasbourg 09 December 1994

21. Case Of Ledyayeva, Dobrokhotova, Zolotareva And Romashina v. Russia (Applications nos. 53157/99, 53247/99, 53695/00 and 56850/00) Judgment Strasbourg 26 October 2006

22. Declaration of the United Nations Conference on the Human Environment Stockholm, 16 June 1972 https:/ https://legal.un.org/avl/ha/dunche/dunche.html\#3

23. N. Levy, Harvard Environmental Law Review, 43(2), 479- 506 (2019)

https://harvardelr.com/ 
24. P. Howard, A. Michael, Harvard Environmental Law Review, 43(1), 120-174 (2019) https://harvardelr.com/ 